\title{
A CONSTITUCIONALIZAÇÃO DO DIREITO PRIVADO E A PROTEÇÃO DOS DIREITOS FUNDAMENTAIS NOS NOVOS ARRANJOS FAMILIARES
}

\author{
THE PRIVATE RIGHT'S CONSTITUTIONALISATION \\ AND PROTECTION OF FUNDAMENTAL RIGHTS \\ IN THE NEW FAMILY'S ARRANGEMANTS
}

\author{
ELISÂNGELA PADILHA ${ }^{1}$
}

\begin{abstract}
RESUMO: O artigo propõe uma reflexão acerca da constitucionalização do direito civil e das repercussões deste movimento no âmbito dos novos arranjos familiares. Para tanto, parte de visão crítica acerca da intervenção do Estado nas relações privadas e da necessidade de proteção aos direitos fundamentais. O direito civil foi o que sofreu de maneira mais intensa o impacto da constitucionalização, pois o próprio conceito de família sofreu significativas transformações e a família casamentária passou a coexistir com diversas modalidades de família. Cada pessoa possui a capacidade de decidir por diferentes formas de convivência e não cabe ao Estado intervir de modo tão intenso na esfera da privacidade familiar. PALAVRAS-CHAVE: Constitucionalização do Direito Privado; Novos Arranjos Familiares; Dignidade da Pessoa Humana.
\end{abstract}

ABSTRACT: The article proposes a reflection on the constitutionalisation of civil law and the repercussions of this movement under the new family arrangements. For this, critical view of part about state intervention in private relationships and the need for protection of fundamental rights. Civil law was the one that suffered more intensely the impact of a constitution, because the very concept of family has undergone significant transformations and casamentária family went to coexist with various family arrangements. Each person has the ability to decide for

Artigo recebido em 05.10.2015. Pareceres emitidos em 08.11.2015 e 03.12.2015.

Artigo aceito para publicação em 16.01.2016.

${ }^{1}$ Advogada. Professora Universitária nas Faculdades Integradas de Ourinhos - FIO (Ourinhos/SP). Mestranda do Programa de Mestrado em Ciências Jurídicas do Centro de Ciências Sociais Aplicadas, Campus Jacarezinho, da Universidade Estadual do Norte do Paraná - UENP. Pós-Graduada em Direito Civil e Processo Civil pelas Faculdades Integradas de Ourinhos FIO/PROJURIS. Graduada em Direito pelas Faculdades Integradas de Ourinhos - FIO. Graduada em Comunicação Social: Publicidade e Propaganda pela Universidade de Marília - UNIMAR. Professora de Direito Civil, Direito Processual Civil e Direitos Humanos e Fundamentais no Curso de Direito das Faculdades Integradas de Ourinhos - FIO. Autora da obra A Eficácia dos Direitos Fundamentais nas Relações Contratuais entre Particulares. padilha.Im@gmail.com 
different ways of living and the state must not intervene so strongly in the sphere of family privacy.

KEYWORDS: Constitutionalization of Private Law; New Living Arrangements; Dignity of Human Person.

SUMÁRIO: Introdução; 1. Dicotomia: direito público e direito privado; 1.1 A Prevalência do Privado sobre o Público; 1.2 A Prevalência do Público sobre o Privado; 1.3 A Relativização da Distinção entre Direito Público e Direito Privado; 2. A Constitucionalização do Direito Privado no Brasil; 2.1 Novos Princípios Informadores do Direito de Família; 2.1.1 Princípio da Proteção da Dignidade da Pessoa Humana; 2.1.2 Princípio da Igualdade; 2.1.3 Princípio da Liberdade ou da Não-intervenção; 3. A Proteção dos Direitos Fundamentais nos Novos Arranjos Familiares; Considerações Finais; Referências Bibliográficas.

SUMMARY: Introduction; 1. Dichotomy: public and private law; 1.1 The Prevalence of the Private over the Public; 1.2 The Prevalence of Public over Private; 1.3 The Relativity of the Distinction between Public Law and Private Law; 2. The Constitutionalization of Private Law in Brazil; 2.1 New Principles Informants Family Law; 2.1.1 Principle of Protection of Human Dignity; 2.1.2 Principle of Equality; 2.1.3 The Principle of Freedom or of Non-intervention; 3. The Protection of Fundamental Rights in the New Family Arrangements; Final Considerations; Bibliographic References.

\section{INTRODUÇÃO}

À família sempre coube um papel essencial na vida do ser humano, representando o modo pelo qual este se relacionava com o meio em que vivia.

No decorrer de cada conjuntura histórica, a organização sóciofamiliar foi sendo moldada e adaptada em consonância com os interesses políticos, econômicos, religiosos e culturais dominantes. De tal modo que, ao fenômeno familiar, implica reconhecer um constante processo de mutação e evolução, eis que influenciado por valores variados decorrentes de circunstâncias de uma determinada época e espaço.

Nas sociedades primitivas, as primeiras manifestações de família constituíram-se com base no instinto sexual, embora não formassem efetivamente uma família para os padrões organizacionais tal como é conhecida. Já no direito romano, a estrutura familiar era tipicamente patriarcal, destacando-se a soberania do pater familias, o casamento monogâmico e heterossexual. No período medieval, a organização familiar sofreu intensa influência religiosa, marcada pela ideia de indissolubilidade do casamento e imperatividade de procriação. Por sua vez, no mundo moderno, o casamento civil foi regulamentado, possibilitando o surgimento de outras modalidades de família. Já no mundo atual, o conceito de família sofreu significativas transformações oriundas do desenvolvimento das ciências, da tecnologia e dos costumes, a partir dos quais a legislação expandiu o seu caráter protetivo, adaptou-se a uma realidade fática, contemporânea, e consignou o novo retrato da família, priorizou a plena realização pessoal de cada membro familiar, com base no afeto, na busca pela felicidade, no respeito à dignidade da pessoa humana e seus direitos fundamentais. 
Sendo assim, a família hodierna apresenta traços que vão além de um mero agrupamento humano. Aquela estrutura rígida da família foi se alterando paulatinamente, alçando novas formas antes inconcebíveis e ganhando visibilidade no panorama legislativo em diversos países do mundo. A família casamentária e decorrente dos laços sagrados do matrimônio passou a coexistir com diversas modalidades de família, tais como a família monoparental, pluriparental, homoafetiva, poliafetiva, a reconstituída, a união estável, enfim, a lista dos múltiplos arranjos familiares é extensa.

No Brasil, especialmente a partir da Constituição Federal de 1988, ocorreram expressivas transformações na estrutura da sociedade e na própria vida das pessoas. Dentre tais mudanças, destaca-se a busca pelo bem-estar de todos, a dignidade da pessoa humana, a igualdade e a liberdade, que ocasionaram um alargamento das relações pessoais, as quais certamente contribuíram para o surgimento de novas estruturas familiares. De lá para cá, aquela composição familiar hierarquizada, patriarcal, matrimonializada e, necessariamente, heterossexual, assistiu à gradual preponderância da afetividade, do respeito, da solidariedade e da liberdade, como elementos na sua composição. Vale dizer, a família tornou-se dinâmica, flexível e não sacralizada.

Desde então, verifica-se que tentar compreender a família apenas sob um ângulo de observação, isolada dos mais variados campos do conhecimento, é enxergá-la de forma míope, desvirtuada de sua real feição. Sem dúvida, torna-se necessária a compreensão da dinâmica e complexidade das modificações sociais perpetradas pelo avanço tecnológico, científico e cultural a fim de abrir espaço para esses novos arranjos familiares suscetíveis às influências da nova sociedade.

O fato é que, embora, de modo geral, a sociedade tenha sido mais civilizada e tolerante quanto às novas estruturas familiares, especialmente com aquelas formadas por casais homoafetivos, os valores patriarcais e 0 conservadorismo social persistem. Apesar das inúmeras mudanças registradas no perfil da família brasileira, alguns grupos ainda insistem em discursos incoerentes com o atual modelo histórico da família, defendendo a manutenção do modelo monogâmico, centralizado na autoridade paterna e, rotuladamente, heterossexual, tal como ocorreu na recente aprovação do Estatuto da Família ${ }^{2}$ que representa verdadeiro retrocesso. Vale dizer, o Estado, de mero fiscalizador (art. 226, § $7^{\circ}, \mathrm{CF}$ ), passa a atuar de maneira intensa e incondicionalmente na vida privada dos cidadãos.

É incontroverso que o direito privado deve sofrer os influxos das opções valorativas do legislador constituinte. No entanto, não se deseja um Estado paternalista que atue imperativamente no âmbito da autonomia privada.

\footnotetext{
${ }^{2}$ Projeto de Lei $n^{\circ}$ 6.583/13, aprovado pela Câmara no dia 08.09.2015. O texto reconhece família como "a entidade familiar formada a partir da união entre um homem e uma mulher, por meio de casamento ou de união estável, e a comunidade formada por qualquer dos pais e seus filhos".
} 
Não se pode, sobretudo, perder de vista as especificidades do direito privado, pois este não pode estar separado, tampouco pode ser absorvido pelo Estado.

Enfim, como proteger juridicamente essa nova realidade marcada pelo pluralismo de relações familiares, que apesar de fugirem do normatizável, nem por isso desmerecem a integral e efetiva proteção do Estado?

Parte-se da premissa de que as pessoas possuem a capacidade de decidirem pelas diferentes formas de convivência, segundo estilos de vida e práticas diferentes, na busca da satisfação pessoal e da felicidade, e não cabe ao Estado intervir de modo tão intenso na esfera da privacidade familiar.

Sendo assim, este estudo visa a analisar o dever do Estado de reconhecer que essas novas modalidades de família são compatíveis com a proteção constitucional, dela extraindo-se a sua tutela. Este trabalho tende, enfim, a propor uma reflexão acerca do papel protetivo do Estado Constitucional perante essa realidade sociológica que são os novos arranjos familiares.

Apesar das inúmeras modificações e do nítido avanço obtidos com a Constituição Federal de 1988, o fato é que as dificuldades e o preconceito em acolher as diversas formações familiares ainda persistem. Valores constitucionais, tais como a igualdade, a liberdade e a dignidade da pessoa humana não são respeitados, o que enseja em marginalização desses grupos na sociedade.

À luz dessas considerações, a realização da pesquisa é de fundamental importância para esse debate sobre a família brasileira, pois contribuirá para os ulteriores desdobramentos, diante da necessidade de se regular e proteger esses novos arranjos familiares e os protagonistas da vida familiar.

\section{DICOTOMIA: DIREITO PÚBLICO E DIREITO PRIVADO}

O fenômeno da constitucionalização do direito privado representa, de certo modo, a superação de uma das grandes dicotomias do pensamento jurídico: o direito público e o direito privado. Deste modo, é necessário percorrer as razões que deram origem a essa diferença, a sua evolução, e por qual motivo tal diferenciação foi relativizada.

Sob o ponto de vista da igualdade e desigualdade, Norberto Bobbio afirma a existência da dicotomia entre o público e o privado, nos seguintes termos:

Com base na forma da relação jurídica, distinguem-se relações de coordenação entre sujeitos de nível igual, e relações de subordinação entre sujeitos de nível diferente, dos quais um é superior e outro inferior: as relações de direito privado seriam caracterizadas pela igualdade dos sujeitos, e seriam, portanto, relações de coordenação; as relações de direito público seriam caracterizadas pela desigualdade dos sujeitos, e seriam, portanto, relações de subordinação. Com base na matéria, porém, que constitui o objeto da relação, distinguem-se os interesses individuais, que se referem a uma única pessoa dos interesses coletivos, que se referem à totalidade das pessoas, à coletividade. Levando em conta esta distinção, o direito privado seria caracterizado pela proteção 
que oferece aos interesses privados e o direito público pela proteção oferecida aos interesses coletivos (BOBBIO, 1984, p. 83).

Para Daniel Sarmento, a dicotomia entre o público e o privado, sobre o ponto de vista da igualdade e desigualdade, reside na distinção na relação de autoridade e subordinação nas relações estabelecidas entre o Estado e o cidadão (público). Por sua vez, no Direito Privado, impera a paridade e coordenação, travadas por agentes em situação de igualdade (2005, p. 31).

Importante ressaltar que o estudo da distinção entre o direito público e o privado sempre vem acompanhado de certo valor axiológico, na medida em que é recorrente a afirmação de que existe supremacia do direito público sobre o privado.

O fato é que, independentemente das distinções que sempre são feitas a partir de critérios variados, originariamente, o direito público e o privado viviam em mundos apartados. Portanto, faz-se necessário um estudo acerca do surgimento dessa dicotomia e sua repercussão no mundo jurídico.

\subsection{A Prevalência do Privado sobre o Público}

Importa enfatizar que a recorrente afirmação da supremacia do direito público sobre o direito privado admitiu alternâncias ao longo da história. Já a evolução não ocorreu de forma linear, ao contrário, verifica-se uma oscilação de modo cíclico.

$\mathrm{Na}$ antiga Grécia, já existia certa relação do público com o privado, haja vista que havia uma participação direta dos cidadãos, na tomada de grandes decisões, no que dizia respeito aos interesses da comunidade. Dentre tais decisões, destacam-se a votação de leis e o julgamento de seus semelhantes em processos públicos mais relevantes. Já em Roma, ao contrário, existia uma nítida separação entre as duas esferas, havendo pouca participação direta dos cidadãos na esfera pública.

Na era medieval, ocorreu certa absorção do público pelo privado, eis que os senhores feudais exerciam verdadeira função pública (FACCHINI NETO, 2006, p. 18).

Com o desenvolvimento do Estado moderno, novamente há uma interrelação entre o público e o privado, pois era evidente o interesse da burguesia emergente no fortalecimento da monarquia nacional, pois isso poderia proporcionar, em especial, o crescimento do comércio e a redução das taxas alfandegárias. Da mesma forma, preocupava-se o monarca com o fortalecimento da burguesia, eis que com isso, poderia cobrar tributos cada vez mais altos e obter maiores empréstimos para o financiamento de suas campanhas militares e outros empreendimentos.

No entanto, por volta do séc. XVIII, a divisão dicotômica entre o público e o privado se mostra mais intensa. $O$ direito público passa a ser visto como o ramo do direito voltado a disciplinar a sociedade civil e a área econômica. Além disso, surgem os primeiros Códigos civis, e as relações privadas começam a 
se desenvolver a partir de uma concepção de propriedade absoluta e de uma plena liberdade contratual (áreas essas que o Direito Público não podia interferir).

Por sua vez, a partir da Revolução Francesa, o direito privado torna-se também burguês, na medida em os Códigos começaram a regular toda a sociedade por meio das ideologias e anseios de um fragmento dessa sociedade, qual seja, a classe burguesa.

Segundo Flávia Piovesan, "há o alargamento do próprio conceito de sujeito de direito, que passou a abranger, além do indivíduo, as entidades de classe, as organizações sindicais, os grupos vulneráveis e a própria humanidade" (1998, p. 130).

Nesse período, os códigos civis desempenhavam o papel de verdadeiras constituições na esfera do direito privado. O direito de propriedade e a autonomia privada eram protegidos como autênticos direitos fundamentais, de maneira quase absoluta. Desta forma, o direito civil oferecia uma espécie de suporte à burguesia para que esta exercesse a sua liberdade sem intervenções do Estado. Daí a importância secundária do direito constitucional.

Já as normas constitucionais daquela época somente tutelavam a autonomia privada para que não houvesse intromissões estatais.

Nesse universo, o direito civil e o direito constitucional percorriam trilhas distintas, cada um com seu próprio domínio de incidência. Aliás, o direito constitucional sequer estabelecia princípios que pudessem disciplinar as relações jurídicas privadas. Como tais constituições não eram rígidas e, portanto, podiam ser alteradas a qualquer tempo, o Code Civil sempre simbolizou a estabilidade da sociedade civil, pois vigora há mais de duzentos anos.

Assentadas tais premissas, resta evidente que o legalismo imperava nessa época. Segundo Nelson Saldanha, ambas as regulamentações jurídicas possuíam uma característica em comum - tratava-se da "concepção legalista e escritural do Direito" (SALDANHA, 1987, p. 78). Por sua vez, a atividade jurisdicional estava reduzida a uma operação técnica, ou seja, o juiz deveria observar os fatos e encontrar a regra legal em um catálogo de leis que resolveria o problema.

\subsection{A Prevalência do Público sobre o Privado}

A era das codificações representou, de certo modo, a prevalência do direito privado sobre o direito público. No entanto, esta relação se inverte no período do constitucionalismo social dos países ocidentais, que sucede ao pós-guerra (FACCHINI, 2006, p. 23-24).

$\mathrm{Na}$ esfera do direito privado, diferentemente do período anterior no qual predominava o individualismo, agora a vontade dos particulares começa a ser limitada, especialmente pelos princípios constitucionais da solidariedade social e da dignidade da pessoa humana. Os códigos, no período anterior, representavam o centro de todo o ordenamento jurídico privado, na medida em que regulavam as relações privadas, sob a proteção da autonomia da vontade. 
Todavia, ao passo em que as novas constituições, com certo olhar para o futuro, pretendiam transformar a sociedade, os novos códigos passaram, também, a ter um caráter promocional. A função dos códigos não se resumia a proteger ou a reprimir os atos que lhes eram contrários, mas, sim, a estimular e encorajar a promoção de atos considerados socialmente úteis (BOBBIO, 1977, p. 13-32).

Com a adoção de microssistemas como, por exemplo, a Lei de Locações, o CDC e o ECA, inicia-se a chamada era dos estatutos.

\subsection{A Relativização da Distinção entre Direito Público e Direito Privado}

Modernamente, sob o ponto de vista jurídico, é possível afirmar que o direito público e o direito privado não caminham em sentidos antagônicos. Isto porque o Estado cada vez mais se aproveita de alguns institutos jurídicos do direito privado quando, por exemplo, celebra contratos com os particulares (nas privatizações).

Por sua vez, o direito privado também percorre as trilhas do direito público na medida em que inúmeros institutos do direito privado passaram a ser protegidos pela Constituição. Sobre este enfoque, destaca-se a função social da propriedade, a função social do contrato, a função social da empresa, a função social da família que, de simples instituição ou mero agrupamento humano baseado em laços sanguíneos, passou a ser reconhecida como um espaço de busca de felicidade e de realização pessoal de cada um de seus membros.

Acerca da relativização da autonomia privada, avalia Konrad Hesse:

La autonomia privada y su manifestación más importante, la libertad contractual, encuentran su fundamento y sus límites en la idea de la configuración bajo propia responsabilidad de la vida y de la personalidad. Presuponen una situación jurídica y fáctica aproximadamente igual de los interesados. Donde falta tal presupuesto, y la autonomia privada de uno conduce a la falta de libertad del outro, desaparece todo fundamento y se transpasa todo límite; el indispensable equilibrio debe entonces ser encontrado por otra via, la de la regulación estatal, cuya eficacia frecuentemente requiere una conexión de preceptos de Derecho Público y Privado. Aquí radica la diferencia esencial entre el significado actual de la autonomia privada y el del siglo XIX: aquél ofrecía una libertad sólo formal, que sólo parcialmente se correspondía con la realidad social; en consecuencia, podía conducir a la falta de libertad efectiva. Una libertad real general nunca puede ser producida por la sola autonomía privada. Dado el presupuesto de una situación jurídica y fáctica aproximadamente igual de los interesados, ésta es, sin embargo, elemento esencial de la libertad real, y como tal no puede ser sustituida por planificación o regulación estatal alguna por cuidada que sea (1995, p. 78-79).

Enfim, após tantas alterações conceituais ao longo da história, direito público e direito privado tiveram seus significados originários modificados. 
Para Maria Celina Bodin de Moraes, "o direito privado deixou de ser o âmbito da vontade individual e o direito público não mais se inspira na subordinação do cidadão" (MORAES, 1993, p. 26). Seria o fim das dicotomias? É indubitável que as diferenças existem (e devem mesmo existir), no entanto, aquela dualidade radical foi atenuada no decorrer das últimas décadas, na medida em que a Constituição Federal de 1988 passou a ser o centro do ordenamento jurídico. As diferenças hoje existentes são puramente quantitativas, pois existe um predomínio dos interesses individuais no direito privado, ao passo que prevalecem os interesses da sociedade no direito público.

\section{A CONSTITUCIONALIZAÇÃO DO DIREITO PRIVADO NO BRASIL}

A constitucionalização do direito privado trouxe reflexos para 0 ordenamento jurídico, conferindo-lhe sistematicidade e unidade. No Brasil, o fenômeno deve ser analisado em duas fases. Na primeira delas, verifica-se que alguns temas que antes eram tratados apenas nos códigos privados (família, propriedade, etc.), passaram a ser disciplinados também nas constituições contemporâneas. Estas passaram, inclusive, a tratar de normas de Direito Penal, Direito Administrativo e Direito Processual. Mas esta é apenas a fase inicial da constitucionalização do Direito, fase esta chamada por alguns estudiosos de relevância constitucional das relações privadas (ALPA,1994, p. 8).

Importante destacar, ainda, que o fenômeno da constitucionalização ocorreu, inicialmente, na Alemanha e, em seguida, na Itália. Já nos países de democratização tardia, tais como Portugal, Espanha e, especialmente, no Brasil, a constitucionalização é recente, embora bastante intensa.

Deste modo, na segunda fase, verifica-se que a Constituição Federal de 1988 passou a ocupar um lugar de destaque no ordenamento jurídico, desfrutando de uma supremacia formal, material e axiológica. Isso conduziu, aqui, ao fenômeno chamado de constitucionalização do direito (ou filtragem constitucional) que é a leitura de toda e qualquer legislação infraconstitucional à luz da Constituição. É a partir da Constituição, portanto, que todo o ordenamento jurídico deve ser filtrado e interpretado (BARROSO, 2005, p. 2).

Sendo assim, a partir da Constituição Federal de 1988, as normas constitucionais ganharam força, alterando o sentido e o alcance de todas as normas infraconstitucionais, com grande repercussão, inclusive, sobre a atuação dos Três Poderes e nas suas relações com os particulares.

Logo, o fenômeno da constitucionalização no Brasil vai muito além do fato de que a Constituição Federal de 1988 passou a tratar de disciplinas próprias do direito privado. O fenômeno deve ser entendido sob a ótica da hermenêutica contemporânea, em um ambiente em que toda matéria verdadeiramente importante carece de interpretação constitucional - direta ou indiretamente.

No mesmo sentido, José Joaquim Gomes Canotilho e Vital Moreira entendem que "a principal manifestação da preeminência normativa da Constituição consiste em que toda a ordem jurídica deve ser lida à luz dela e passada pelo seu crivo" (CANOTILHO; MOREIRA, 1991, p. 45). 
Nesse ambiente, o direito civil foi o que sofreu de maneira mais intensa o impacto da constitucionalização. O antigo Código Civil, que tinha a pretensão de disciplinar todos os aspectos da vida privada, acaba sendo esfacelado pela edição de várias leis específicas tratando de temas como divórcio, locação, sociedades empresariais, filiação, criança e adolescente, alimentos, etc. Enfim, uma verdadeira descodificação (fragmentação) do direito civil.

Daí falar-se em repersonalização (ou despatrimonialização) do direito civil. O ser humano passou a ser o centro do direito civil e o patrimônio deixou de ser o centro das preocupações privatistas. Sobre o maior relevo dado à pessoa, Pietro Perlingieri salienta que "os interesses e direitos de natureza essencialmente pessoal antepõem-se a interesses e direitos patrimoniais, 0 que supõe que na hierarquia de valores a pessoa humana prevalece sobre o interesse econômico" (1983, p. 2).

Além disso, por consequência da constitucionalização do direito civil, alguns princípios constitucionais, em especial o da dignidade da pessoa humana, acabaram migrando para o âmbito do direito privado. Nas palavras de Ingo Wolfgang Sarlet, "a dignidade da pessoa humana é simultaneamente limite e tarefa dos poderes estatais" (SARLET, 2004, p. 311).

Por outro lado, diante de tantos novos estatutos tratando de temas do direito privado, é preciso garantir certa unidade sistemática por meio de interpretação constitucional. Sobre o tema, Pietro Perlingieri ressalta que "o Código Civil certamente perdeu a centralidade de outrora. O papel unificador do sistema é desempenhado de maneira cada vez mais incisiva pelo Texto Constitucional" (1999, p. 6).

Nesse sentido, objetivando trazer harmonia ao ordenamento jurídico, em consequência do caráter normativo da Constituição, todas as leis e atos da administração pública devem ser interpretados à luz dos valores e princípios consagrados na Constituição Federal de 1988.

Mas também ao Judiciário impende invalidar os atos legislativos que sejam incompatíveis com a Constituição, desde que não haja inovação na ordem jurídica. O debate, todavia, é complexo e carece de outros estudos.

Em suma, o fenômeno da constitucionalização implica na irradiação de todos os valores constitucionais por todo o sistema jurídico. Disto resulta a aplicação direta da Constituição Federal de 1988 a diversas pretensões ou a interpretação das normas infraconstitucionais à luz dos valores constitucionais. Em especial, o Direito Civil brasileiro tomou como norma vinculante os princípios constitucionais.

O grande desafio, no entanto, é superar um antigo problema, a distância abismal entre a proclamação dos valores constitucionais e a efetivação.

\subsection{Novos Princípios Informadores do Direito de Família}

Necessário reconhecer que a mudança de paradigmas no direito privado, decorrente da releitura imprescindível de todo o ordenamento jurídico à luz da 
Constituição Federal de 1988, promoveu uma verdadeira reestruturação no Direito de Família, agora implementado por novos princípios.

\subsubsection{Princípio da Proteção da Dignidade da Pessoa Humana}

O artigo $1^{\circ}$, inciso III, da Constituição Federal de 1988 dispõe que o Estado Democrático de Direito tem como fundamento a dignidade da pessoa humana. Igualmente, a Declaração Universal de Direitos Humanos da ONU reconheceu no primeiro parágrafo de seu preâmbulo um valor ético que deveria ser utilizado como base de todos os direitos ali previstos, qual seja: a dignidade da pessoa humana.

Todavia, não é tarefa fácil conceituar o princípio da dignidade da pessoa humana. Segundo Immanuel Kant, é uma qualidade congênita e inalienável de todos os seres humanos, a qual impede a sua coisificação e se materializa através da capacidade de autodeterminação que os indivíduos possuem por meio da razão. Isso ocorre porque os seres humanos têm, na manifestação da sua vontade, o poder de determinar suas ações, de acordo com a ideia de cumprimento de certas leis que adotam, sendo essa característica exclusiva dos seres racionais (2002, p. 56, 62-63).

Para Jürgen Habermas, no entanto, a dignidade humana não é uma propriedade inata ou biológica dos indivíduos, como a inteligência ou a cor dos olhos, as quais eles possuem por natureza, mas ela consiste em uma espécie de inviolabilidade que assume significado somente nas relações interpessoais de mútuo respeito, decorrente da igualdade de direitos presentes nas relações entre as pessoas (2003, p. 33).

Verifica-se, portanto, que o princípio de proteção da dignidade da pessoa humana deve ser o ponto central da discussão atual envolvendo as relações familiares.

\subsubsection{Princípio da Igualdade}

O artigo 5 , caput, da Constituição Federal de 1988 consagra o princípio da igualdade.

"Temos o direito a ser iguais quando a diferença nos inferioriza; temos o direito a ser diferentes quando a igualdade nos descaracteriza", afirma Boaventura de Souza Santos (2009, p. 18).

Para Alexandre de Moraes:

O princípio da igualdade consagrado pela Constituição opera em dois planos distintos. De uma parte, frente ao legislador ou ao próprio executivo, na edição, respectivamente, de leis, atos normativos e medidas provisórias, impedindo que possa criar tratamentos abusivamente diferenciados a pessoas que se encontram em situações idênticas. Em outro plano, na obrigatoriedade ao intérprete, basicamente, a autoridade pública, de aplicar a lei e atos normativos de maneira igualitária, sem estabelecimento de diferenciações em razão de sexo, religião, convicções filosóficas ou políticas, raça, classe social (2011, p. 87). 
No Direito de Família, é necessário combater a discriminação em nome da máxima eficácia do direito fundamental à igualdade.

\subsubsection{Princípio da Liberdade ou da Não-intervenção}

A Constituição Federal de 1988 reconhece um amplo rol de liberdades. Por sua vez, o artigo 1513 do Código Civil dispõe que "É defeso a qualquer pessoa de direito público ou direito privado interferir na comunhão de vida instituída pela família". Trata-se da consagração do princípio da liberdade ou da não-intervenção na ótica do Direito de Família.

Segundo Thomas Hobbes, "por liberdade entende-se a ausência de impedimentos externos; impedimentos que muitas vezes tiram parte do poder de cada um fazer o que quer".

José Afonso da Silva afirma que liberdade consiste na "possibilidade de coordenação consciente dos meios necessários à realização da felicidade pessoal" (2002, p. 232).

Já Daniel Sarmento conceitua liberdade como "o poder que a pessoa tem de auto regulamentar os próprios interesses" (2005, p. 188).

Sendo assim, a garantia de que cada indivíduo atue de forma livre, autônoma, é corolário da existência de uma sociedade livre e democrática.

No que concerne ao Direito de Família, cabe a cada indivíduo decidir com quem vai se relacionar. Deve existir uma esfera de atuação meramente privada. O papel do Estado acerca do casamento é sair do caminho e, quando isso não for possível, deve exercer o seu papel garantindo que as pessoas possam conduzir suas vidas e de suas famílias da forma que acharem melhor.

No entanto, de nada adianta atribuir poder ao indivíduo para que tome decisões segundo as suas convicções, sem que the sejam dados subsídios e condições para que tais escolhas sejam concretizadas. A igualdade de ordem puramente formal não satisfaz. Em síntese, o Estado deve propiciar o exercício efetivo da liberdade, deve garantir que as pessoas possam livremente decidir a respeito de sua personalidade, das suas escolhas afetivas e sexuais, das questões existenciais, ainda que estas estejam dissonantes daquela composição familiar hierarquizada, patriarcal, matrimonializada e, necessariamente, heterossexual.

\section{A PROTEÇÃO DOS DIREITOS FUNDAMENTAIS NOS NOVOS ARRANJOS FAMILIARES}

A Constituição Federal de 1988 erigiu a família como base da sociedade e, consequentemente, conferiu-Ihe especial proteção do Estado. Mas quando se diz que a família é o núcleo essencial da sociedade, é preciso ter claro que não se faz referência àquela família tal como concebida historicamente, ou seja, aquela composição familiar patrimonializada, hierarquizada e matrimonializada, predominante no século anterior e no Código Civil de 1916. Tampouco se faz referência ao que foi decidido pela comissão especial do Estatuto da Família, ao aprovar a redação do Projeto de Lei $n^{0}$ 6.583/2013, que define a 
família como "o núcleo formado a partir da união entre um homem e uma mulher". Quanto a isto, não há dúvidas de que o Brasil levantou a bandeira do retrocesso, pois a dignidade da pessoa humana acaba de ser negada. Refere-se, no presente estudo, à família tal como ela é hoje: plural.

Sendo assim, quando se fala em novos arranjos familiares, refere-se às diferentes modalidades de convivência familiar e que têm o vínculo afetivo como sua principal característica. Passou-se a falar em entidade familiar, atentando-se muito mais ao afeto que une seus integrantes do que à sua forma. Para Luiz Edson Fachin, "não é mais o indivíduo que existe para a família e para o casamento, mas a família e o casamento existem para o seu desenvolvimento pessoal, em busca de sua aspiração à felicidade" (1999, p. 10).

Logo, o princípio da afetividade, entrelaçado a outros princípios, passou a nortear toda e qualquer decisão ou concepção acerca desses novos arranjos familiares.

Conforme já mencionado, a Constituição Federal de 1988 também trouxe expressivas transformações, pois a partir de seus princípios fundamentais, entre eles a dignidade da pessoa humana, a igualdade e a liberdade, rompeu definitivamente com antigas concepções já consagradas, tais como a ilegitimidade dos filhos, uma vez que todas as formas de filiação foram legitimadas pelo Estado; a superioridade do homem sobre a mulher nas relações conjugais; 0 casamento como única forma de se constituir e legitimar a família (PEREIRA, 2003 , p. 14). Com relação às novas formas de convívio, a Constituição acolheu os anseios da sociedade e abarcou pelo menos três, quais sejam: a família proveniente do casamento, a família proveniente da união estável e a família monoparental.

Todavia, apesar dos significativos avanços trazidos pela Constituição, o fato é que várias outras formas de convivência familiar não foram inseridas no texto constitucional - o que, a princípio, leva a crer que elas não existem ou, se existem, não constituem entidades familiares e, portanto, não merecem a devida tutela do Estado.

De qualquer modo, a lista dos diversos arranjos familiares é bastante extensa e a família casamentária passou a coexistir com a família monoparental, pluriparental, homoafetiva, poliafetiva, recomposta, casais com filhos de casamentos anteriores e seus novos filhos, mães criando filhos sem os pais por perto e vice-versa, casais sem filhos, filhos sem pais, meninos de rua e na rua; parentalidade socioafetiva, inseminações artificiais, barriga solidária etc. (PEREIRA, 2003, p. 13). Tais mudanças no perfil da família brasileira, nas últimas décadas, foram registradas pelo $\mathrm{IBGE}^{3}$.

Como, enfim, proteger juridicamente essa nova realidade marcada pelo pluralismo de relações familiares, que apesar de fugirem do normatizável,

\footnotetext{
${ }^{3}$ A coleta do Censo Demográfico 2010 foi realizada no período de $1^{\circ}$ de agosto a 30 de outubro de 2010.
} 
nem por isso desmerecem a integral e efetiva proteção do Estado? Neste sentido, assevera a professora Giselda Hironaka:

(...) biológica ou não, oriunda do casamento ou não, matrilinear ou patrilinear, monogâmica ou poligâmica, monoparental ou poliparental, não importa. Nem importa o lugar que o indivíduo ocupe no seu âmago; se o de pai, se o de mãe, se o de filho. O que importa é pertencer ao seu âmago; é estar naquele idealizado lugar, onde é possível integrar sentimentos, esperanças, valores e se sentir, por isso, a caminho da realização de seu projeto de felicidade pessoal $(1999$, p. 8).

O fato é que as pessoas possuem a capacidade de decidirem pelas diferentes formas de convivência, segundo estilos de vida e práticas diferentes, na busca da satisfação pessoal e da felicidade, e não cabe ao Estado intervir de modo tão intenso na esfera da privacidade familiar. Ao contrário, cabe ao Estado reconhecer que essas novas modalidades de família são compatíveis com a proteção constitucional, dela extraindo-se a sua tutela, especialmente no que tange à proteção dos direitos fundamentais.

Afirmar que os direitos fundamentais vinculam o Estado beira a banalidade (VIEIRA, 2001, p. 2012), embora o art. $5^{0}$, \& $1^{0}$ da Constituição Federal de 1988 tenha se limitado a proclamar a aplicabilidade imediata das normas de direitos fundamentais sem, contudo, prever a vinculação dos Poderes Públicos. Essa ausência, todavia, não elide a responsabilidade estatal de respeitar, proteger e promover ativamente os direitos fundamentais, especialmente no âmbito das relações familiares. Aliás, não existe ato de entidade pública que seja livre dos direitos fundamentais (CANOTILHO, 1992, p. 591, apud, SARLET, 2012, p. 374).

O art. $5^{0}$, § $1^{\circ}$ da Constituição Federal de 1988 estabelece que "as normas definidoras dos direitos e garantias fundamentais têm aplicabilidade imediata". Trata-se de um instrumento de extrema relevância para os direitos fundamentais, mas que suscita controvérsias quanto ao significado e alcance da aplicabilidade imediata.

Nesse sentido, entende-se que os direitos fundamentais, por força do art. $5^{\circ}, \S 1^{\circ}$ da Constituição Federal de 1988, são normas diretamente aplicáveis pelos Poderes Legislativo, Executivo e Judiciário, na medida em que estão investidos do poder-dever de promover as condições necessárias para tornar os direitos fundamentais reais e efetivos. Trata-se da teoria da eficácia vertical dos direitos fundamentais.

Sendo assim, no que concerne à vinculação do Poder Legislativo, este se encontra proibido de editar leis contrárias aos direitos fundamentais. Vale dizer, não são as leis que definem o conteúdo dos direitos fundamentais, mas estes é que constituem verdadeiros parâmetros na elaboração daquelas. A vinculação do Legislativo, enfim, não se resume à proibição de edição de leis contrárias aos direitos fundamentais, mas, especialmente, ao dever de 
uma proteção ativa, no sentido de elaborar leis que busquem aprimorar a legislação vigente harmonizando-a com os direitos fundamentais.

No que tange ao Direito de Família, objeto do presente estudo, é preciso legitimar os novos arranjos familiares, pois na medida em que o conceito de família foi flexibilizado em seu desenvolvimento histórico, esta adquiriu um caráter eminentemente social e passou a ser identificada pelo afeto.

É indiscutível que o Legislativo não consegue prever ou acompanhar todas as necessidades humanas, haja vista que estas são inúmeras e não obstante se transformam com o decorrer do tempo, igualmente adquirem contornos variados conforme o caso concreto. Por outro, a partir da constatação e reconhecimento dessas novas modalidades de família, o Direito não poderá negar os seus efeitos jurídicos, mas tão somente criar instrumentos jurídicos hábeis para possibilitar o exercício dessas práticas em que o desejo se manifesta.

É preciso, sobretudo, respeitar o direito à liberdade na formação familiar, no sentido de conferir aos indivíduos o direito de constituição de determinada entidade familiar, de planejamento da prole, de acesso às diferentes vias de filiação - natural, adotiva ou decorrente de assistência às técnicas de reprodução assistida, segundo os seus valores mais íntimos.

É necessário, ainda, que sejam respeitados os direitos da personalidade, possibilitando às pessoas o direito de autodeterminação, de individualidade.

Enfim, incluir no quadro legislativo a proteção dos novos arranjos familiares, considerando o direito à liberdade, igualdade e a dignidade humana como fundamentos estruturantes é o que se espera Segundo Dimitri Dimoulis, "Um direito que não consegue regulamentar as relações sociais de forma que corresponda aos anseios da população não encontra aceitação e perde sua legitimidade" (2013, p. 255).

Deve-se reconhecer também a vinculação do Poder Executivo aos direitos fundamentais. Significa que os órgãos administrativos devem executar as leis e pronunciar as suas decisões em consonância com os direitos fundamentais.

Importante lembrar que, na esfera da discricionariedade que dispõe o Poder Público, a prática de atos administrativos contrários aos direitos fundamentais poderá dar ensejo à invalidação judicial desses atos.

Por fim, no que tange à vinculação do Poder Judiciário aos direitos fundamentais, estes devem determinar e direcionar não apenas as decisões judiciais, como também todos os atos praticados no exercício das funções jurisdicionais.

Além disso, o Judiciário ainda exerce o controle de constitucionalidade dos atos dos demais órgãos públicos, declarando a inconstitucionalidade dos atos contrários à Constituição do Brasil de 1988 e, de modo especial, aos direitos fundamentais. Aliás, as próprias decisões judiciais que ofenderem aos 
direitos fundamentais poderão ser fiscalizadas pelo STF, na condição de guardião constitucional.

Também compete ao Judiciário, com sensibilidade e prudência para não ultrapassar os limites contidos no sistema jurídico, interpretar e aplicar os textos legais em consonância com os direitos fundamentais, adequando-os ao Direito, mantendo-os vivos, quando houver eventual lacuna. Tem-se a necessidade, enfim, de um Judiciário que explore mais as potencialidades da Constituição, investindo em interpretação principiológica e prestigiando, especialmente, os direitos fundamentais nas relações familiares. Tudo isto, certamente, não transforma o Judiciário em legislador e, consequentemente, não oferece riscos à democracia.

O Judiciário pode e deve assegurar a eficácia desses direitos sem, contudo, trazer riscos para a legitimidade democrática, utilizando-se ainda do instrumento fornecido pelo art. $4^{\circ}$ da Lei de Introdução às Normas do Direito Brasileiro, de acordo com o qual: "Quando a lei for omissa, o juiz decidirá o caso de acordo com a analogia, os costumes e os princípios gerais de direito".

Em um Estado Democrático de Direito, fundado no valor da dignidade da pessoa humana, cada pessoa possui uma esfera de liberdade e autonomia individuais que deve ser assegurada pelo Estado. Por isso, a violação aos direitos fundamentais deve ser rechaçada por todos, quer ela decorra do Poder Público ou do Poder Privado.

Por derradeiro, é evidente que o Estado deve respeitar, proteger e promover ativamente os direitos fundamentais no que tange aos novos arranjos familiares. Todavia, não se deseja um Estado paternalista que atue invadindo e limitando, demasiadamente, a esfera da autonomia pessoal. Deve existir uma esfera mínima de atuação exclusivamente privada, que fique longe do domínio estatal, em que os indivíduos são livres para escolher as pessoas com quem vão se relacionar, podem associar-se com quem quiserem e pelos motivos que quiserem, podem negar-se a entrar em determinado estabelecimento por quaisquer motivos, e podem ainda regular todas estas situações por meio de um contrato com o conteúdo que quiserem (UBILLOS, 2006, p. 335).

De todo o exposto, necessário se faz nutrir-se de várias maneiras de encarar a realidade das famílias contemporâneas. (SALLES, 1994, p. 160). É preciso, por meio de uma hermenêutica extensiva da legislação, estender as relações familiares para além do direito positivado, ao contrário de engessá-las. Torna-se imprescindível, sobretudo, impedir que a história das exclusões perpetradas pelo Direito de Família se repita. Excluir determinados modelos familiares, tratando-os como mera sociedade de fato, significa retirar a dignidade das pessoas que os constituíram, negando-lhes uma série de direitos.

Enfim, deve-se buscar uma efetiva concretização dos direitos fundamentais que, dentre seus múltiplos papeis na sociedade, deve garantir a dignidade. Apesar dos avanços expressivos, ainda há uma longa trilha a percorrer. 


\section{CONSIDERAÇÕES FINAIS}

Ao final deste estudo, é possível compendiar algumas das principais ideias desenvolvidas nas proposições que seguem.

A Constituição Federal de 1988 passou a ocupar um lugar de destaque no ordenamento jurídico, desfrutando de uma supremacia formal, material e axiológica. Isso conduziu, aqui, ao fenômeno chamado de constitucionalização do direito que é a leitura de toda e qualquer legislação infraconstitucional à luz da Constituição. É a partir da Constituição, portanto, que todo o ordenamento jurídico deve ser filtrado e interpretado. Toda matéria verdadeiramente importante carece de interpretação constitucional - direta ou indiretamente.

Nesse ambiente, o direito civil foi o que sofreu de maneira mais intensa o impacto da constitucionalização.

Além disso, por consequência da constitucionalização do direito civil, alguns princípios constitucionais, em especial o da dignidade da pessoa humana, acabaram migrando para o âmbito do direito privado.

O conceito de família também sofreu significativas transformações. A família casamentária e decorrente dos laços sagrados do matrimônio passou a coexistir com diversas modalidades de família, tais como a família monoparental, pluriparental, homoafetiva, poliafetiva, a reconstituída, a união estável etc.

Quando se fala em novos arranjos familiares, refere-se às diferentes modalidades de convivência familiar que prioriza a plena realização pessoal de cada membro familiar, com base no afeto, na busca pela felicidade, no respeito à dignidade da pessoa humana e seus direitos fundamentais.

Cada pessoa possui a capacidade de decidir por diferentes formas de convivência, segundo estilos de vida e práticas diferentes, na busca da satisfação pessoal e da felicidade, e não cabe ao Estado intervir de modo tão intenso na esfera da privacidade familiar. Ao contrário, cabe ao Estado reconhecer que essas novas modalidades de família são compatíveis com a proteção constitucional, dela extraindo-se a sua tutela, especialmente no que tange à proteção dos direitos fundamentais. Excluir determinados modelos familiares, tratando-os como mera sociedade de fato, significa retirar a dignidade das pessoas que os constituíram, negando-lhes uma série de direitos.

É preciso, enfim, que os Poderes Legislativo, Executivo e Judiciário estejam comprometidos na busca por uma efetiva concretização dos direitos fundamentais nas relações familiares que, dentre seus múltiplos papeis na sociedade, deve garantir a dignidade.

\section{REFERÊNCIAS BIBLIOGRÁFICAS}

ALPA, Guido. Introduzione allo Studio Critico del Diritto Privato. Torino: G. Giappichelli Editore, 1994.

BARROSO, Luís Roberto. Diferentes, mas Iguais: o reconhecimento jurídico das relações homoafetivas no Brasil. Revista Diálogo Jurídico. Salvador, 2007, nº 16, maio, junho, julho, agosto. 
. Interpretação e Aplicação da Constituição: fundamentos de uma dogmática jurídica transformadora. 7. ed., São Paulo: Saraiva, 2009.

Neoconstitucionalismo e Constitucionalização do Direito: O triunfo tardio do Direito Constitucional no Brasil. Jus Navigandi, Teresina, 01 de novembro de 2005. Disponível em: <http://jus.com.br/artigos/7547/neoconstitucionalismo-e-constitucionalizacaodo-direito>. Acesso em: 27 out. 2013.

O Direito Constitucional e a Efetividade de suas Normas. 3. ed., Rio de Janeiro: Renovar, 1996.

BOBBIO, Norberto. Dalla Struttura alla Funzione. Nuovi Studi di Teoria del Diritto. Milano: Edizione di Comunità, 1977.

BOBBIO, Noberto. Direito e Estado no Pensamento de Immanuel Kant. Brasília: Universidade de Brasília, 1984.

CANOTILHO, José Joaquim Gomes; MOREIRA, Vital. Fundamentos da Constituição. Coimbra: Coimbra, 1991.

DIMOULIS, Dimitri. Manual de Introdução ao Estudo do Direito. 5. ed., São Paulo: Revista dos Tribunais, 2013.

FACHIN, Luiz Edson. Inovação e Tradição do Direito de Família Contemporâneo sob o Novo Código Civil Brasileiro. Disponível em: <http://www.anima-opet.com.br/pdf/anima3Luiz-Edson-Fachin.pdf>. Acesso em 29 nov. 2013.

FACHIN, Luiz Édson; RUZYK, Carlos Eduardo Pianovski. Direitos Fundamentais, Dignidade da Pessoa Humana e o Novo Código Civil: uma análise crítica. Rio de Janeiro: Renovar, 2001. In: SARLET, Ingo Wolfgang. (Org.). Constituição, Direitos Fundamentais e Direito Privado. 2. ed., Porto Alegre: Livraria do Advogado, 2006.

. Curso de Direito Civil. 2. ed., Rio de Janeiro: Renovar, 2003.

. Da Paternidade: relação biológica e afetiva. Belo Horizonte: Del Rey, 1998.

. Direito de Família: elementos críticos à luz do novo Código Civil brasileiro. Rio de Janeiro: Renovar, 2003.

. Elementos Críticos do Direito de Família: curso de direito civil. Rio de Janeiro: Renovar, 1999.

FACHINNI NETO, Eugênio. Reflexões Histórico-evolutivas sobre a Constitucionalização do direito privado. In: SARLET, Ingo Wolfgang. (Org.). Constituição, Direitos Fundamentais e Direito Privado. 2. ed., Porto Alegre: Livraria do Advogado, 2006.

HABERMAS, Jürgen. The Future of Human Nature. Malden: Blackwell Publishing Inc., 2003.

HESSE, Konrad. A Força Normativa da Constituição. Porto Alegre: Fabris, 1991.

. Derecho Constitucional y Derecho Privado. Madrid: Ed. Civitas, 1995.

HIRONAKA, Giselda Maria Fernandes Novaes. Família e Casamento em Evolução. In: Revista Brasileira de Direito de Família. Porto Alegre: Síntese, nº 1, abr./maio/jun. 1999. HOBBES, Thomas. Leviatã. São Paulo. Abril Cultural. Capítulo XIV.

IBGE. CENSO DEMOCRÁFICO 2010. Disponível em <http://censo2010.ibge.gov.br/ resultados/resumo.html>. Acesso em: 25 jan. 2016.

KANT, Immanuel. Groundwork of the Metaphysic of Morals. In: PASTERNACK, Lawrence. Immanuel Kant: Groundwork of the Metaphisic of Morals. New York: Routledge, 2002, p. 56, 62-63. 
Derecho Constitucional y Derecho Privado. Madrid: Civitas, 1995.

MORAES, Alexandre de. Direito Constitucional. 21. ed., São Paulo: Atlas, 2007.

Direitos Humanos Fundamentais. 9. ed., São Paulo: Atlas, 2011.

MORAES, Maria Celina Bodin de. A Caminho de um Direito Civil Constitucional. Revista de Direito Civil, nº 65, 1993.

PEREIRA, Rodrigo da Cunha. Família, Direitos Humanos, Psicanálise e Inclusão Social. In: Revista Brasileira de Direito de Família. Porto Alegre: Síntese, a. IV, n 16 , jan./fev./mar. 2003.

. Família. Disponível em: <http://dspace.c3sl.ufpr.br/dspace/bitstream/handle/ 1884/2272/Tese_Dr.\%20Rodrigo\%20da?sequence=1>. Acesso em: 19 set. 2014.

PERLINGIERI, Pietro. Perfis do Direito Civil; Introdução ao Direito Civil Constitucional. Tradução Maria Cristina de Cicco. Rio de Janeiro: Renovar, 1999.

PIOVESAN, Flávia. Temas de Direitos Humanos. São Paulo: Max Limonad, 1998.

. Igualdade, Diferença e Direitos Humanos: perspectiva global e regional. In: LEITE, George Salomão; SARLET, Ingo Wolfgang (Orgs.). Direitos Fundamentais e Estado Constitucional: Estudos em homenagem a J. J. Gomes Canotilho. São Paulo: Revista dos Tribunais, 2009.

SALDANHA, Nelson. Conceituações do Direito: tendência privatizante e tendência publicizante. Revista de Direito Público, São Paulo, Revista dos Tribunais, vol. 81, jan./março, 1987.

p. 188.

Direitos Fundamentais e Relações Privadas. Rio de Janeiro: Lumen Juris, 2005,

SALLES, Vania. Novos Olhares sobre a Família. Disponível em: <http://www.abep.nepo. unicamp.br/docs/rev_inf/vol11_n2_1994/vol11_n2_1994_4artigo_159_170.pdf>. Acesso em: 19 set. 2014.

SANTOS, Boaventura de Souza de. Revista de Direitos Humanos: o Desafio da Interculturalidade, $\mathrm{n}^{\circ} 2$, jun. 2009.

SARLET, Ingo Wolfgang. A Eficácia dos Direitos Fundamentais: uma teoria geral dos direitos fundamentais na perspectiva constitucional. 11. ed., Porto Alegre: Livraria do Advogado, 2012.

. A Dignidade da Pessoa Humana e Direitos Fundamentais. 3. ed., rev. atual. ampl. Porto Alegre: Livraria do Advogado, 2004.

. As Dimensões da Dignidade da Pessoa Humana: construindo uma compreensão jurídico-constitucional necessária e possível. In: SARLET, Ingo Wolfgang. (Org.). Dimensões da Dignidade - Ensaios de Filosofia do Direito e Direito Constitucional. 2. ed., Porto Alegre: Livraria do Advogado, 2009, p. 15-43.

SARMENTO, Daniel. Direitos Fundamentais e Relações Privadas. Rio de Janeiro: Lúmen Júris, 2006. Júris, 2008.

Direitos Fundamentais e Relações Privadas. 2. ed., Rio de Janeiro: Lúmen

"Interesses Públicos vs. Interesses Privados na Perspectiva da Teoria e da Filosofia Constitucional". In Interesses Públicos versus Privados: desconstruindo o princípio da supremacia do interesse público. SARMENTO, Daniel (org.). Rio de Janeiro: Lumen Juris, 2005. 
SILVA, José Afonso da. Curso de Direito Constitucional Positivo. 20. ed., São Paulo: Malheiros, 2002.

STRECK, Lenio Luiz. O que é isto: decido conforme minha consciência? Porto Alegre: Livraria do Advogado, 2010.

TEPEDINO, Gustavo. Temas de Direito Civil. Rio de Janeiro: Renovar, 1999.

UBILLOS, Juan María Bilbao. ¿ En qué medida vinculan a los particulares los derechos fundamentales? In: SARLET, Ingo Wolfgang. (Org.). Constituição, Direitos Fundamentais e Direito Privado. 2. ed., Porto Alegre: Livraria do Advogado, 2006. 